Article

\title{
Experimental Data Assessment and Fatigue Design Recommendation for Stainless-Steel Welded Joints
}

\author{
Yang Peng, Jie Chen and Jun Dong * \\ College of Civil Engineering, Nanjing Tech University, Nanjing 210000, China \\ * Correspondence: dongjun@njtech.edu.cn; Tel.: +86-136-0140-7837
}

Received: 12 June 2019; Accepted: 25 June 2019; Published: 26 June 2019

\begin{abstract}
Stainless steel possesses outstanding advantages such as good corrosion resistance and long service life. Stainless steel is one of the primary materials used for sustainable structures, and welding is one of the main connection modes of stainless-steel bridges and other structures. Therefore, fatigue damage at welded joints deserves attention. The existing fatigue design codes of stainless-steel structures mainly adopt the design philosophy of structural steel. In order to comprehensively review the published fatigue test data of welded joints in stainless steel, in this paper, the fatigue test data of representative welded joints of stainless steel were summarized comprehensively and the $S-N$ curves of six representative stainless-steel welded joints were obtained by statistical evaluation. The comparison of the fatigue strength from existing design codes and fatigue test data was performed, and the results showed that the fatigue strength of welded joints of stainless steel was higher than that of structural-steel welded joints. The flexibility of regression analysis with and without a fixed negative inverse slope was discussed based on the scatter index. It was found that the fatigue test data of stainless-steel welded joints are more consistent with the $S-N$ curve regressed by a free negative inverse slope. In this paper, a design proposal for the fatigue strength of representative welded joints of stainless steel is presented based on the $S-N$ curve regressed by the free negative inverse slope.
\end{abstract}

Keywords: stainless-steel structure; welded joints; fatigue strength; $S-N$ curves; scatter index

\section{Introduction}

Stainless steel has outstanding corrosion resistance, an elegant surface effect, and good mechanical properties. With the improvement of engineering construction standards, the optimal life cycle benefits are taken into account, as well as the realization of targets to reuse materials for energy conservation and emission reduction. Therefore, stainless steel is one of the preferred materials for a sustainable structure, and has wide development prospects in environments with high durability requirements for materials such as offshore or near the sea [1-3]. The upper tower of Stonecutters Bridge is a composite structure with a stainless-steel skin. The Hong Kong-Zhuhai-Macau Bridge's outer reinforcement parts used duplex stainless steel [4]. The designers of the motorway flyover in Kerensheide, the Netherlands, took the resulting corrosion risks into account by selecting stainless steel. The pillars of the footbridge in Reykjavik, Iceland consist of concrete-filled stainless-steel circular hollow sections. The structure of the Spain Añorga Railway Bridge is completely made from stainless steel [5]. Stockholm Bridge in Sweden used duplex stainless steel in its renovation. Welding is the main method of connection, and fatigue is the main design criterion. The repair of defects is very expensive; moreover, it is difficult to obtain the ideal repair effect [6-9]. Thus, guidelines are needed to avoid fatigue failure of stainless-steel welded joints.

The fatigue properties of welded joints were tested due to difficulties in reaching a consensus on the fatigue design rules. The collection of existing fatigue test data is a common practice in classifying fatigue details. This is, of course, not the most advisable way, given that the costs and the time involved 
in testing specimens to simulate real bridge details and loads are considerable. Data representative of several countries, steel, and manufacturers may be considered so that the natural scatter based on bridge constructions is included.

The fatigue behavior of stainless-steel welded joints was the subject of substantial research. Niemi et al. $[10,11]$ studied the fatigue strength of welded joints of austenitic and duplex stainless steel. They tested the butt-welded specimens and several types of fillet-welded specimens. The results indicated that the fatigue strength of stainless-steel welded joints was higher than that of the welded joints of structural steel existing in the fatigue design standard [11]. Razmjoo [12] summarized fatigue test data of stainless-steel welded joints in 1995 . He compared the data with the $95 \%$ confidence limits enclosing the fatigue data obtained from structural-steel welded joints. He found that the fatigue test data of stainless-steel welded joints fell within the scatter band of the structural-steel welded joints. Due to data limitation, he suggested that the $S-N$ curves for structural-steel welded joints could be used to conservatively design stainless-steel welded joints. Branco et al. [13] systematically investigated the fatigue behavior of stainless-steel welded joints. They compared the fatigue test data of stainless-steel welded joints with the scatter band of the structural-steel welded joints. The results indicated that the $S-N$ curves of the structural-steel welded joints could be applied to stainless-steel welded joints. The International Institute of Welding (IIW) fatigue recommendation [14] S-N curves were generally more suitable than those in Eurocode (EC)3 Parts 1-9 [15]. They found that the type of stainless steel did not influence the fatigue strength of stainless-steel welded joints. The specimens made from gas tungsten arc welding (GTAW) have high fatigue strength due to the very favorable weld profiles and low stress concentration. Metrovich et al. [16] studied the fatigue strength of the weld in stainless-steel beams. These beams were made from AL-6XN superaustenitic steel; this stainless steel is popular in the chemical industry. They found that the fatigue strength of the longitudinal fillet weld and bulkhead attachment was the same as a structural-steel weld and the fatigue strength of the transverse groove weld was higher than a structural-steel weld. The National Research Institute for Metals of Japan [17] published fatigue test data of the hot-rolled austenitic stainless-steel and butt weld. Nakamura et al. $[18,19]$ investigated the fatigue strength of the butt weld and the filled weld made from austenitic stainless steel in the air and a corrosive environment. The results illustrated that the negative inverse slope of $S-N$ curves $(m=5-15)$ regressed from the fatigue test data was much larger than the Japanese fatigue design standard [20] for the structural-steel welded joints, in which the negative inverse slope $m$ of the $S-N$ curves in the standard is equal to 3 . In the corrosive environment, the fatigue strength was reduced. The fatigue strengths of the butt weld and the fillet weld in the corrosive environment were $80 \%$ and $66 \%$ of the fatigue strength in the air environment, respectively. Singh et al. [21,22] tested the butt weld and the fillet weld of the austenitic stainless steel, and the results indicated that the fatigue test data were consistent with the fatigue design standard, BS 5400 Part 10 [23]. Wu et al. [24] studied the butt weld and the fillet weld made from austenitic stainless steel, duplex stainless steel, and typical structural steel. They found that the fatigue strength of welded joints made from stainless steel was higher than that of the structural-steel welded joints. The $S-N$ curves obtained from the fatigue test data of stainless-steel welded joints were quite different from the $S-N$ curves from the IIW fatigue design recommendation [14]. The negative inverse slope of the $S-N$ curves and the fatigue strength regressed from Wu's fatigue test data were substantially larger than those in the IIW fatigue design recommendation. However, a systematical statistical analysis of the fatigue test data is absent in these studies. Highly conservative design rules were proposed, owing to the fact that experimental evidence was not available to justify more favorable rules. The conclusion is based on the design rules for structural-steel welded joints although the stress-strain curves for stainless steels exhibit no yielding plateau [25], as well as a low proportional limit [25] and low residual stress [26].

The above research focused on the nominal stress approach. Partanen and Niemi [27] proposed $S-N$ curves for a hot-spot stress approach based on the fatigue test data of structural-steel and austenitic stainless-steel welded joints. The fatigue strength that resulted in a fatigue life of two million cycles was $107 \mathrm{MPa}$. This value for the fatigue strength was similar to that of the fatigue classification of the 
IIW recommendation [14] and EC3 Parts 1-9 [15]. Jia et al. [28] found that the fatigue strength of duplex stainless-steel welded joints with a fatigue life of two million cycles was equal to $167 \mathrm{MPa}$. This was much higher than the result of Partanen and Niemi. Feng and Young [29] investigated the stress concentration factor (SCF) of tubular X-joints. They illustrated that the current SCF equations gave unconservative predicted results, and new SCF equations were proposed. The research on hot-spot stress approach for stainless-steel welded joints is not sufficient to suggest reasonable fatigue design rules. Lazzarin et al. [30,31] studied two new approaches for fatigue estimation of stainless-steel welded joints: a local strain energy density approach and a peak stress method. The results showed that the local strain energy density approach was not suitable, and the peak stress method could accurately estimate the fatigue performance of stainless-steel welded joints. Further validation of the peak stress method should be conducted. Fracture mechanics were used to investigate the fatigue strength of stainless-steel welded joints [12,21,22,32-34]. The fatigue crack propagation of stainless steel is influenced by the transformation-induced plasticity (TRIP) effect [35]. The TRIP effect was confirmed to be beneficial to the fatigue crack growth resistance of stainless steels containing austenite as the main phase, such as austenitic stainless steels [35]. This TRIP effect was ignored in the fracture mechanics research for stainless-steel welded joints. After recent developments in the field of stainless-steel construction, it is necessary to conduct a comparative study on the commonly used design standards.

In the fatigue design standards of steel structures, the IIW recommendation [15] and EC3 Parts 1-9 [14] include stainless steel. The IIW recommendation [15] includes austenitic stainless steel and EC3 Parts 1-9 [14] include all grades of stainless steel. The fatigue classifications of the six typical welded joints in EC3 Parts 1-9 [14] and the IIW recommendation [15] are shown in Table 1. There is a slight difference between these standards. The fatigue strength of the plates with longitudinal edge gussets in EC3 Parts 1-9 [14] is lower than that in the IIW recommendation [15].

Table 1. Fatigue strength of typical welded joints in the European Eurocode (EC)3 Parts 1-9 and the International Institute of Welding (IIW) recommendation.

\begin{tabular}{|c|c|c|c|}
\hline Weld Structure & Additional Provisions & EC3 Codes [14] & IIW Codes [15] \\
\hline \multirow{2}{*}{ Butt weld } & Weld reinforcement less than $10 \%$ width & 80 & 80 \\
\hline & Weld reinforcement less than $20 \%$ width & 90 & 90 \\
\hline $\begin{array}{l}\text { Cruciform joints failing } \\
\text { in the weld throat }\end{array}$ & Failing in the weld throat & 36 & 36 \\
\hline $\begin{array}{l}\text { Plates with transverse } \\
\text { fillet-welded attachments }\end{array}$ & l & 80 & 80 \\
\hline \multirow{4}{*}{$\begin{array}{l}\text { Plates with longitudinal } \\
\text { fillet-welded attachments }\end{array}$} & $\mathrm{L} \leq 50 \mathrm{~mm}$ & 80 & 80 \\
\hline & $50 \mathrm{~mm}<\mathrm{L} \leq 80 \mathrm{~mm}$ & 71 & 71 \\
\hline & $80 \mathrm{~mm}<\mathrm{L} \leq 100 \mathrm{~mm}$ & 63 & 63 \\
\hline & $\mathrm{L}>100 \mathrm{~mm}$ & 56 & 50 \\
\hline $\begin{array}{l}\text { Plates with longitudinal } \\
\text { edge gussets }\end{array}$ & $\mathrm{L}<150 \mathrm{~mm}$ & 40 & 50 \\
\hline $\begin{array}{l}\text { Fillet-welded joints with } \\
\text { longitudinal round pipes }\end{array}$ & / & 80 & 80 \\
\hline \multirow{3}{*}{ Base metal } & Plates and flats with as-rolled edges & 160 & 160 \\
\hline & $\begin{array}{l}\text { Machine gas cut or sheared material } \\
\text { with subsequent dressing }\end{array}$ & 140 & 140 \\
\hline & $\begin{array}{l}\text { Material with machine gas cut edges } \\
\text { having shallow and regular drag lines } \\
\text { or manual gas cut material, } \\
\text { subsequently dressed to remove all } \\
\text { edge discontinuities }\end{array}$ & 125 & 125 \\
\hline
\end{tabular}


Thus, it is an opportune time to review the fatigue test data of welded joints. In this paper, the fatigue test data of the welded joints of stainless steel were summarized, and the $S-N$ curve and the fatigue strength were obtained using a statistical analysis method. This paper discusses the applicability of a free negative inverse slope regression $S-N$ curve and a fixed negative inverse slope regression $S-N$ curve using the scatter index, $T_{\sigma}$. The fatigue classification of stainless steel followed that of structural steels in Eurocode 3 [14] and the International Institute of Welding recommendations [15]; however, the difference in welding processes and so on between stainless steel and structural steel was not taken into account. By comparing the fatigue classification of Eurocode 3 and IIW recommendations with the fatigue test data of stainless-steel welded joints, the applicability of fatigue classification of structural steel for stainless steel is assessed. In this paper, a design proposal for the fatigue strength of stainless-steel welded joints is presented.

\section{Database for the Evaluation}

\subsection{Data-Pooling of Experimental Results}

Fatigue test data of typical welded joints of stainless steel were collected from Japan $[17,18]$, India [21], Europe [11-13], and China [24]. Data including a total of 85 butt welds and 45 cruciform joints failing in the weld throat, 41 plates with transverse fillet-welded attachments, 38 plates with longitudinal fillet-welded attachments, 38 plates with longitudinal edge gussets, and 10 fillet-welded joints with longitudinal round pipes were obtained. The specimen thickness, welding procedure, material type, experimental information, and the fatigue crack initiation position are shown in Table 2. 
Table 2. Fatigue test data for stainless steel.

\begin{tabular}{|c|c|c|c|c|c|c|c|c|c|}
\hline Weld Joint Type & Data Source & $\begin{array}{c}\text { Material } \\
\text { Trademark }\end{array}$ & $\begin{array}{l}\text { Ultimate Tensile } \\
\text { Strength (MPa) }\end{array}$ & Steel Type & $\begin{array}{l}\text { Thickness } \\
(\mathrm{mm})\end{array}$ & $\begin{array}{c}\text { Stress Ratio, } \\
\text { R }\end{array}$ & $\begin{array}{l}\text { Frequency, } \mathrm{f} \\
(\mathrm{Hz})\end{array}$ & $\begin{array}{l}\text { Welding } \\
\text { Procedure }\end{array}$ & $\begin{array}{l}\text { Crack Initiation } \\
\text { Position }\end{array}$ \\
\hline \multirow{8}{*}{ Butt weld } & [17] & SUS304 & 520 & Austenitic & 20 & $-1,0,0.5$ & $1-10$ & - & Weld toe \\
\hline & [18] & SUS304 & 520 & Austenitic & 12 & $0,0.5$ & $1-5$ & - & Weld toe \\
\hline & \multirow{2}{*}{ [13] } & S31803 & 640 & Duplex & \multirow{2}{*}{10} & $0.1,0.5$ & \multirow{2}{*}{$10-20$} & GTAW & Weld toe \\
\hline & & $304 \mathrm{~L}$ & 520 & Austenitic & & $0.1,0.5$ & & GMAW & Weld toe \\
\hline & [21] & $304 \mathrm{~L}$ & 520 & Austenitic & 6 & 0 & 30 & GMAW-GTAW & Weld toe \\
\hline & \multirow{3}{*}{ [12] } & 316 & 620 & \multirow{3}{*}{ Austenitic } & - & 0 & - & - & - \\
\hline & & $316 \mathrm{~L}$ & 485 & & \multirow{2}{*}{-} & 0.1 & \multirow{2}{*}{-} & \multirow{2}{*}{-} & \multirow{2}{*}{-} \\
\hline & & $304 \mathrm{~L}$ & 485 & & & 0 & & & \\
\hline \multirow{3}{*}{$\begin{array}{c}\text { Load-carrying cruciform } \\
\text { joint }\end{array}$} & \multirow{2}{*}{ [13] } & S31803 & 640 & Duplex & 10 & $0.1,0.5$ & \multirow{2}{*}{-} & GTAW & \multirow{3}{*}{ Weld root } \\
\hline & & $304 \mathrm{~L}$ & 520 & Austenitic & 10 & $0.1,0.5$ & & GMAW & \\
\hline & [24] & 1Cr18Ni9Ti & 550 & Austenitic & 7 & 0.1 & - & SMAW & \\
\hline \multirow{5}{*}{$\begin{array}{l}\text { Plates with transverse } \\
\text { fillet-welded attachments }\end{array}$} & \multirow{2}{*}{ [13] } & S31803 & 640 & Duplex & \multirow{2}{*}{10} & $0.1,0.5$ & \multirow{2}{*}{$10-20$} & GTAW & \multirow{2}{*}{ Weld toe } \\
\hline & & $304 \mathrm{~L}$ & 520 & Austenitic & & $0.1,0.5$ & & GMAW & \\
\hline & \multirow{3}{*}{ [11] } & Grade1.4301 & 625.55 & Austenitic & \multirow{2}{*}{8} & & \multirow{3}{*}{-} & \multirow{3}{*}{-} & \multirow{3}{*}{ Weld toe } \\
\hline & & Grade1.4462 & 640 & Duplex & & $0.1-0.41$ & & & \\
\hline & & Grade1.4436 & 520 & Austenitic & 12 & & & & \\
\hline \multirow{3}{*}{$\begin{array}{l}\text { Plates with longitudinal } \\
\text { fillet-welded attachments }\end{array}$} & \multirow{2}{*}{ [13] } & S31803 & 640 & Duplex & \multirow{2}{*}{10} & $0.1,0.5$ & \multirow{2}{*}{$10-20$} & GTAW & \multirow{2}{*}{ Weld toe } \\
\hline & & $304 \mathrm{~L}$ & 520 & Austenitic & & $0.1,0.5$ & & GMAW & \\
\hline & [24] & 1Cr18Ni9Ti & 550 & Austenitic & 7 & 0.1 & - & SMAW & Weld toe \\
\hline \multirow{3}{*}{$\begin{array}{l}\text { Plates with longitudinal } \\
\text { edge gussets }\end{array}$} & \multirow{2}{*}{ [13] } & S31803 & 640 & Duplex & 10 & $0.1,0.5$ & 10 & GTAW & - \\
\hline & & $304 \mathrm{~L}$ & 520 & Austenitic & 10 & $0.1,0.5$ & $10-20$ & GMAW & 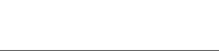 \\
\hline & [24] & SAF2205 & 620 & Duplex & 7 & 0.1 & - & GMAW & Weld toe \\
\hline $\begin{array}{l}\text { Fillet-welded joints with } \\
\text { longitudinal round pipes }\end{array}$ & [24] & 1Cr18Ni9Ti & 550 & Austenitic & 8 & 0.1 & - & GMAW & Weld toe \\
\hline Base metal & [18] & SUS304 & 520 & Austenitic & 12 & $0,0.5$ & $1-5$ & - & base metal \\
\hline Dase metal & [21] & $304 \mathrm{~L}$ & 520 & Austenitic & 6 & 0 & 30 & MIG & Base metal \\
\hline
\end{tabular}

Note: Shielded metal arc welding (SMAW) in the welding process involves manual arc welding, gas metal arc welding (GMAW) involves inert gas shielded arc welding, and gas tungsten arc welding (GTAW) involves non-consumable electrode gas shielded arc welding. 
It should be mentioned that the fatigue data from the literature should be verified using the log-normal distribution because of the heterogeneous nature of the database. Statistical examinations for proving the quality of the data being merged were applied to check if each dataset could be regarded as part of the same population. Checking that datasets belonged to the same statistical population was also applied to identify parameters that led to a differentiation in the fatigue category. The details can be found in Section 2.2.

It is well known that, with the increase of plate thickness, the fatigue life of welded joints will decrease [36]. Therefore, most fatigue rules include a correction factor, which can reduce the stress obtained from the design $S-N$ curve when the thickness of the plate exceeds a certain reference value. The design curve can be directly applied. In the EC3 Part 9 [14] and IIW recommendations [15], the reference thickness is $25 \mathrm{~mm}$. In Table 1, the thickness of specimens was $6 \mathrm{~mm}$ to $12 \mathrm{~mm}$ and was much smaller than the reference thickness. The plate thickness correction cannot be studied due to limited data. It is well known that the fatigue strength of welded joints is not related to the material property [36], i.e., the tensile strength. The tensile strength of the duplex stainless steel is much higher than that of the austenitic stainless steel. Maddox [36] reviewed the current research, and the results demonstrated that the influence of the material type on the fatigue strength for stainless-steel welded joints can be neglected. Following the above conclusion and considering the fact that some data did not include the material strength, the influence of material type was not studied in the present paper.

Stainless steel is a rate-sensitive material; however, a load frequency between 3 and $114 \mathrm{~Hz}$ has no effect on fatigue behavior when the temperature does not increase and there is no corrosion during the test period [37]. In this paper, the normal distribution of test data under different load frequencies was tested, and it was found that the test data of different load frequencies still satisfied the normal distribution. Therefore, the load frequency indirectly affects the fatigue behavior.

The stress ratio does not influence the fatigue strength of the welded joints. Branco et al. [13] found the same conclusion for stainless-steel welded joints. However, small-scale specimens were tested in their experiments. To the best of the authors' knowledge, no large-scale specimen (welded beam) data could be found in the published literature. These should be researched in the future to reach a solid conclusion.

The different welding procedures produce different weld profiles and imperfections. From a general view, the weld quality represents the weld profile and imperfections [38]. The weld quality has a significant influence on the fatigue strength of the welded joints [38]. Branco et al. [13] reported that there was no difference between the specimens made from gas metal arc welding (GMAW) and from gas tungsten arc welding (GTAW). The weld quality of these two welding procedures can be regarded as being the same.

The crack initiation position is related to the weld profile. This should be illustrated in the fatigue classification category. Except for the load-carrying cruciform joint, the fatigue crack initiation occurs at the weld toe in the other welded joints, as shown in Table 2.

These fatigue test data summarized in Table 1 can be used to determine the fatigue strength of the stainless-steel welded joints. The thickness effect can be studied by using thicker specimens and collecting more beam specimen data in the future.

\subsection{Examination of the Log-Normal Distribution}

The statistical samples used in regression $S-N$ curves had systematic errors that were too large; therefore, the consequences would not be credible. As such, it was necessary to judge whether the systematic error of data could be neglected before regressing the $S-N$ curve.

The fatigue life data, $y=\log N$, were prepared for $n$ specimens for probability plotting by ranking the data from minimum to maximum values. Each data item was labeled with an order number, $i$, as $y_{1} \leq y_{2} \leq \ldots \leq y_{n}$. The probability of survival for the $i$ th data item was approximated as follows:

$$
p_{i}=1-\frac{i}{n+1}
$$


Statistical tests for verifying the quality of the data being merged were applied to check if each sample set could be seen as part of the same population. The logarithmic fatigue life obeys a normal distribution [39]. As shown in Figure 1, the logarithmic fatigue life was chosen as the abscissa and the survival probability was chosen as the ordinate. When the test data satisfy the normal distribution, the data are reasonably linear on a probability graph [39,40]. An "eyeball" assessment was used to determine whether the logarithmic fatigue life data in the normal probability graph followed a linear trend [40].

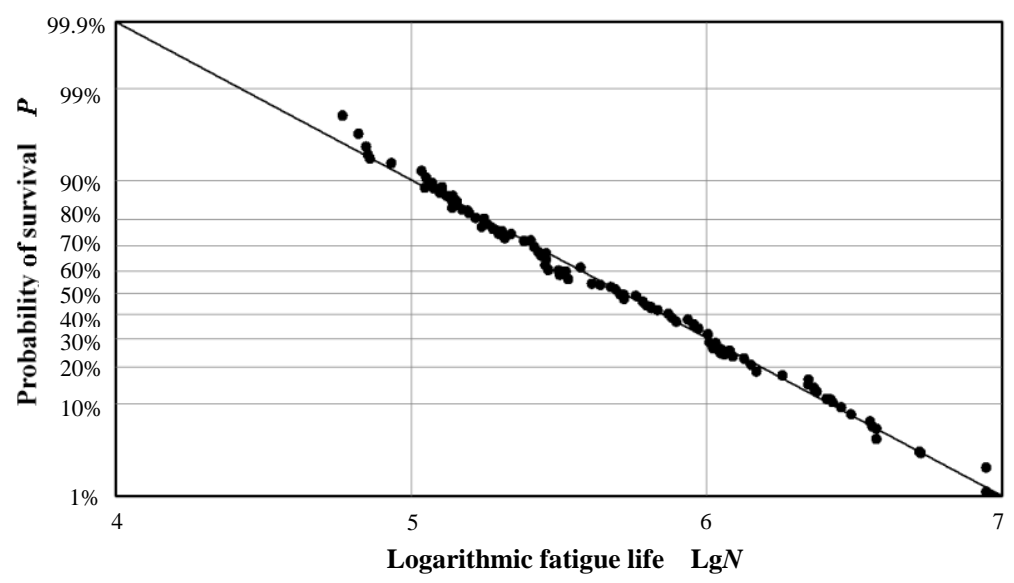

(a)

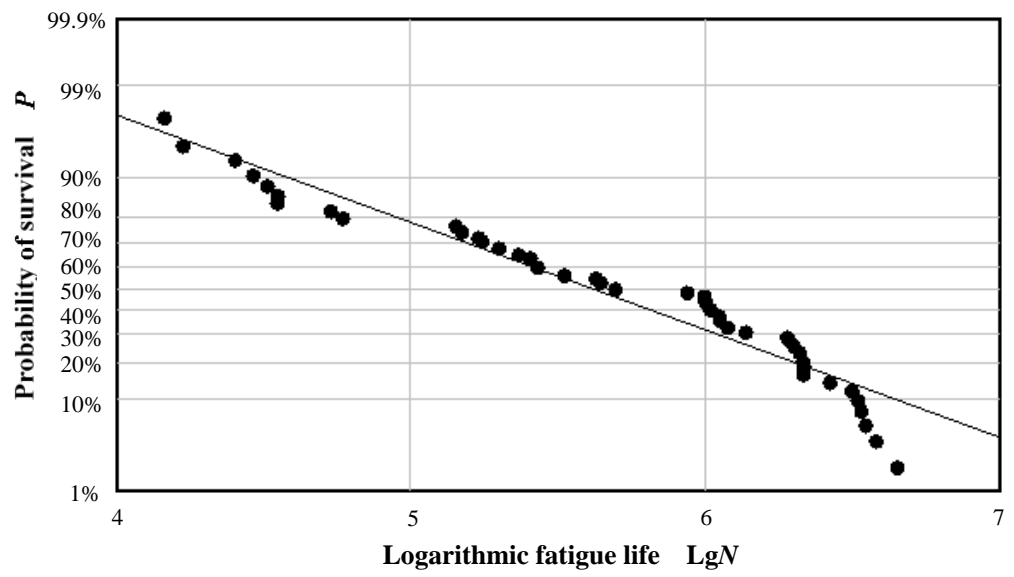

(b)

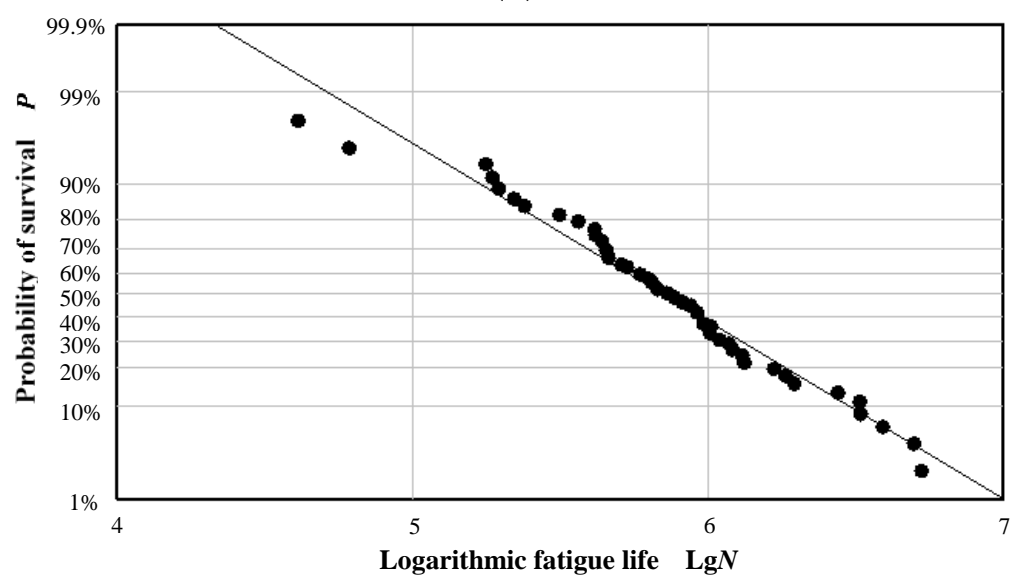

(c)

Figure 1. Cont. 


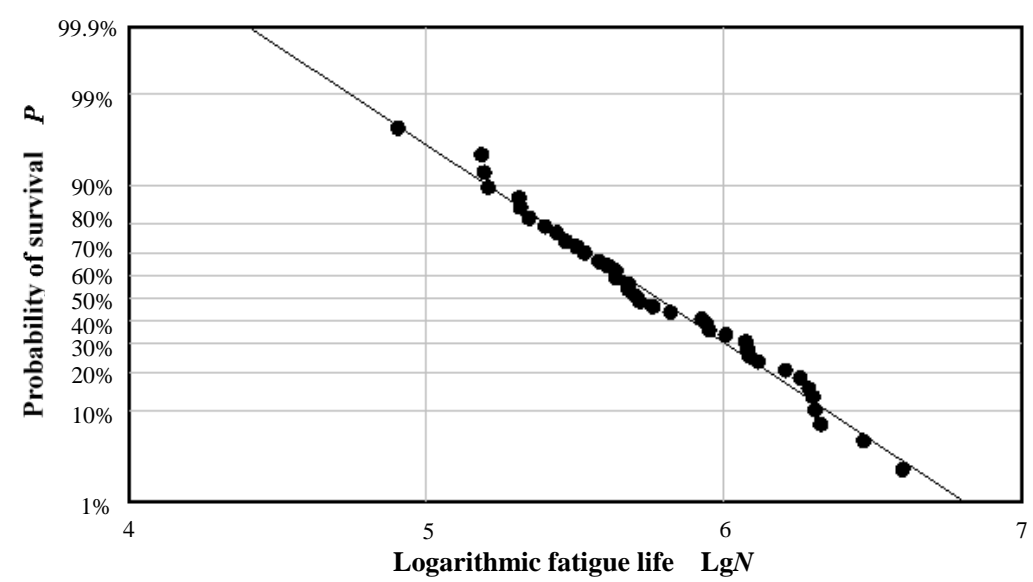

(d)

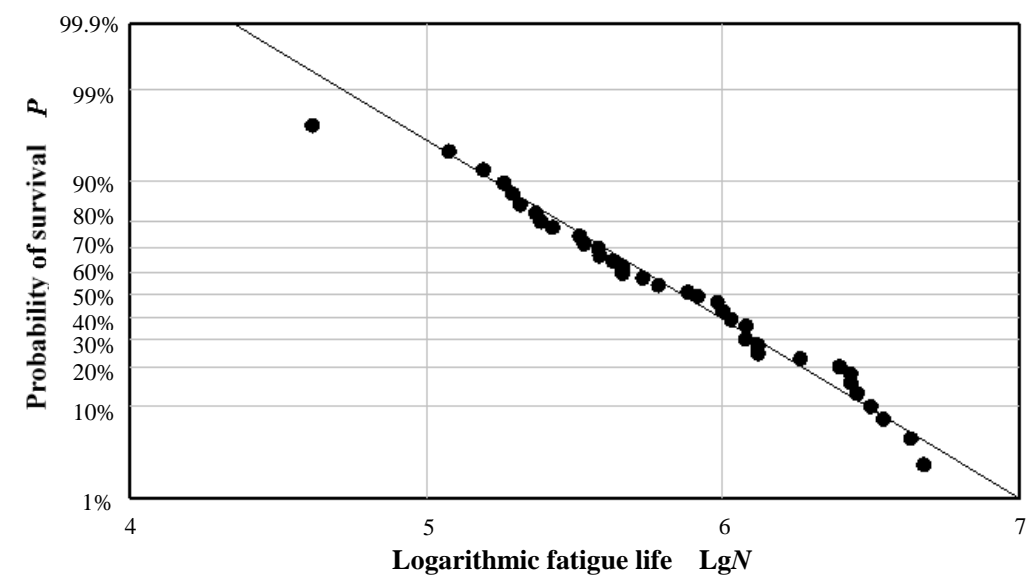

(e)

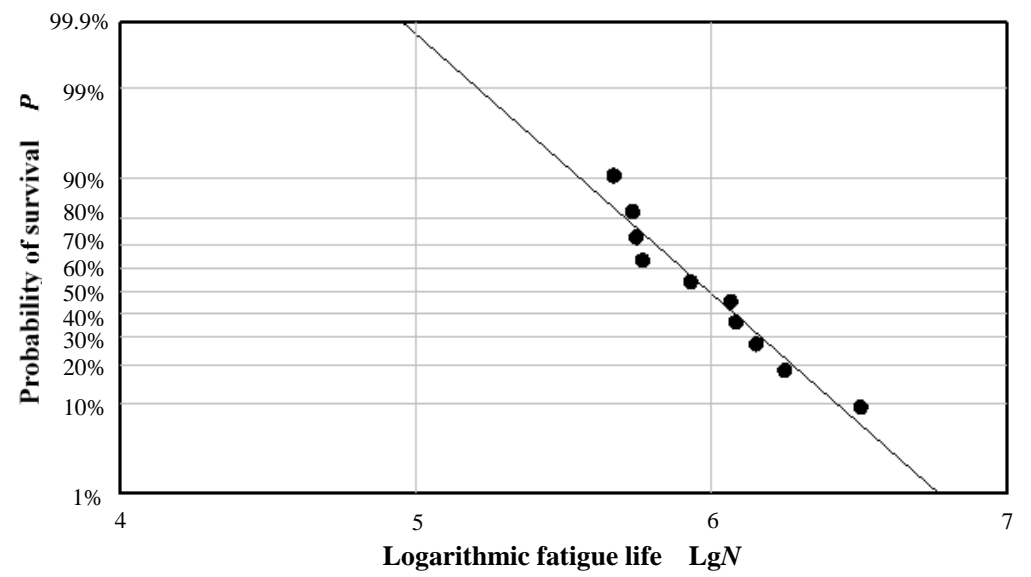

(f)

Figure 1. Cont. 


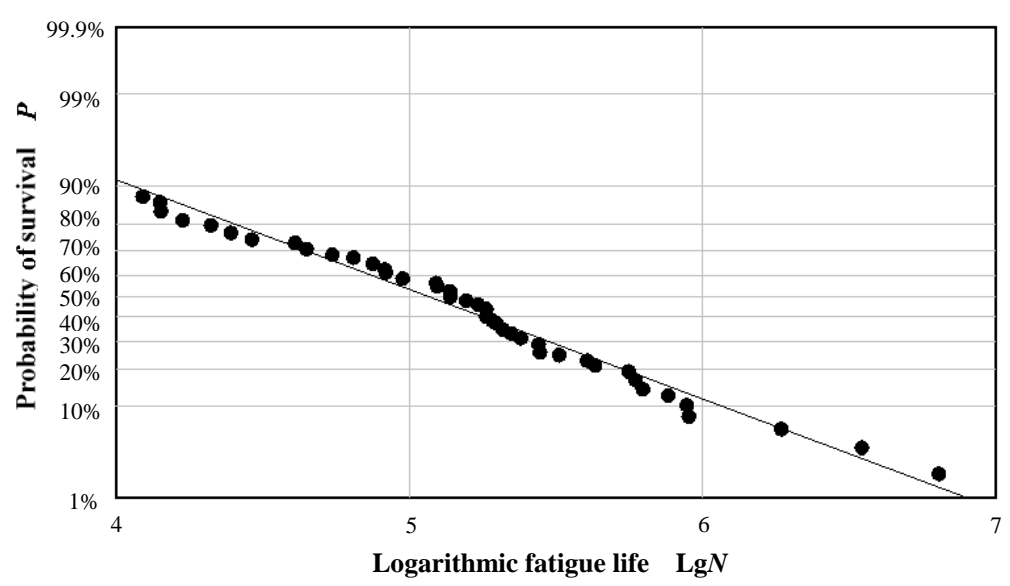

(g)

Figure 1. Verification of the normal distribution of fatigue test data: (a) butt weld; (b) cruciform joints failing in the weld throat; (c) plates with transverse fillet-welded attachments; (d) plates with longitudinal fillet-welded attachments; (e) plates with longitudinal edge gussets; (f) fillet-welded joints with longitudinal round pipes; (g) base metal.

The distribution of data points was close to linear, which indicates that the data conformed to a normal distribution. The collected fatigue test data could be regarded as samples from the same statistical matrix and were in accordance with the normal distribution. It was found that the test data of different steel types, thicknesses, stress ratios, load frequencies, and welding procedures still satisfied the normal distribution. Therefore, these factors indirectly affected the fatigue behavior of the test data. The test data collected could be utilized to regress the $S-N$ curve.

\section{Statistical Re-Analysis, $S-N$ Curves, and Fatigue Strength}

\section{1. $S-N$ Curve}

Taking the stress range $\log \Delta \sigma$ as an independent variable and the number of cycles $\log N$ as dependent, the mean fatigue $S-N$ curve was obtained by estimating both the negative inverse slope $m$ and the intercept $\log C$ as follows:

$$
\begin{gathered}
C=\Delta \sigma^{m} N \Rightarrow \log N=\log C-m \log \Delta \sigma, \\
m=\frac{\sum_{i=1}^{n}\left(y_{i}-\bar{y}\right)^{2}}{\sum_{i=1}^{n}\left(x_{i}-\bar{x}\right)\left(y_{i}-\bar{y}\right)}, \\
\log C=\bar{x}+\frac{\sum_{i=1}^{n}\left(x_{i}-\bar{x}\right)\left(y_{i}-\bar{y}\right)}{\sum_{i=1}^{n}\left(y_{i}-\bar{y}\right)^{2}} \bar{y},
\end{gathered}
$$

where $y$ represents the logarithmic fatigue life and $x$ represents the logarithmic stress amplitude; $\bar{y}$ represents the mean of logarithmic fatigue life and $\bar{x}$ represents the mean of logarithmic stress amplitude.

$$
x_{k}=x_{m}-k_{(p, 1-\alpha, v)} \cdot \sigma .
$$

As shown in Equation (5), the characteristic $S-N$ curve was obtained by translating the mean $S-N$ curve, and the translation distance was $k \cdot \sigma \cdot y_{\mathrm{m}}$ represents the logarithmic fatigue life of the mean $S-N$ curve, and $y_{\mathrm{k}}$ represents the logarithmic fatigue life of the characteristic $S-N$ curve. $\sigma$ represents the 
standard deviation estimator of the logarithmic fatigue life, while $k$ is correlated with the probability of survival $p_{s}$, degree of confidence $\alpha$, and degree of freedom $\gamma$. The characteristic value for the fatigue strength was defined with a survival probability of $95 \%$ at a one-sided confidence level of $75 \%$ at $2 \times 10^{6}$ cycles. The IIW recommendation refers to the logarithmic fatigue life of the average $S-N$ curve minus two standard deviations, corresponding to a $97.7 \%$ survival probability [15]. The characteristic $S-N$ curve obtained at $k=2$ is lower than the $S-N$ curve calculated by Equation (5) [41]. In this paper, the characteristic $S-N$ curve was obtained by referring to the method of IIW recommendation.

Figure 2 shows the fatigue test data of six typical welded joints and the fitting characteristics of the $S-N$ curve. In order to analyze the rationality of applying the fatigue classification of structural steel to stainless steel, Figure 2 also shows the fatigue classification curves of structural steel. The negative inverse slope of the characteristic $S-N$ curve regressed freely was obtained from the test data using the least squares regression method; the negative inverse slope of the fixed slope regression $S-N$ curves and fatigue classification curves adopted a value of 3 .

The number of fatigue test data points of the six typical welded joints collected in this paper was more than 10, which satisfied the conditions and could be regressed freely. For ease of comparison, the regression $S-N$ curves with a fixed slope $m=3$ are also given in Figure 2.

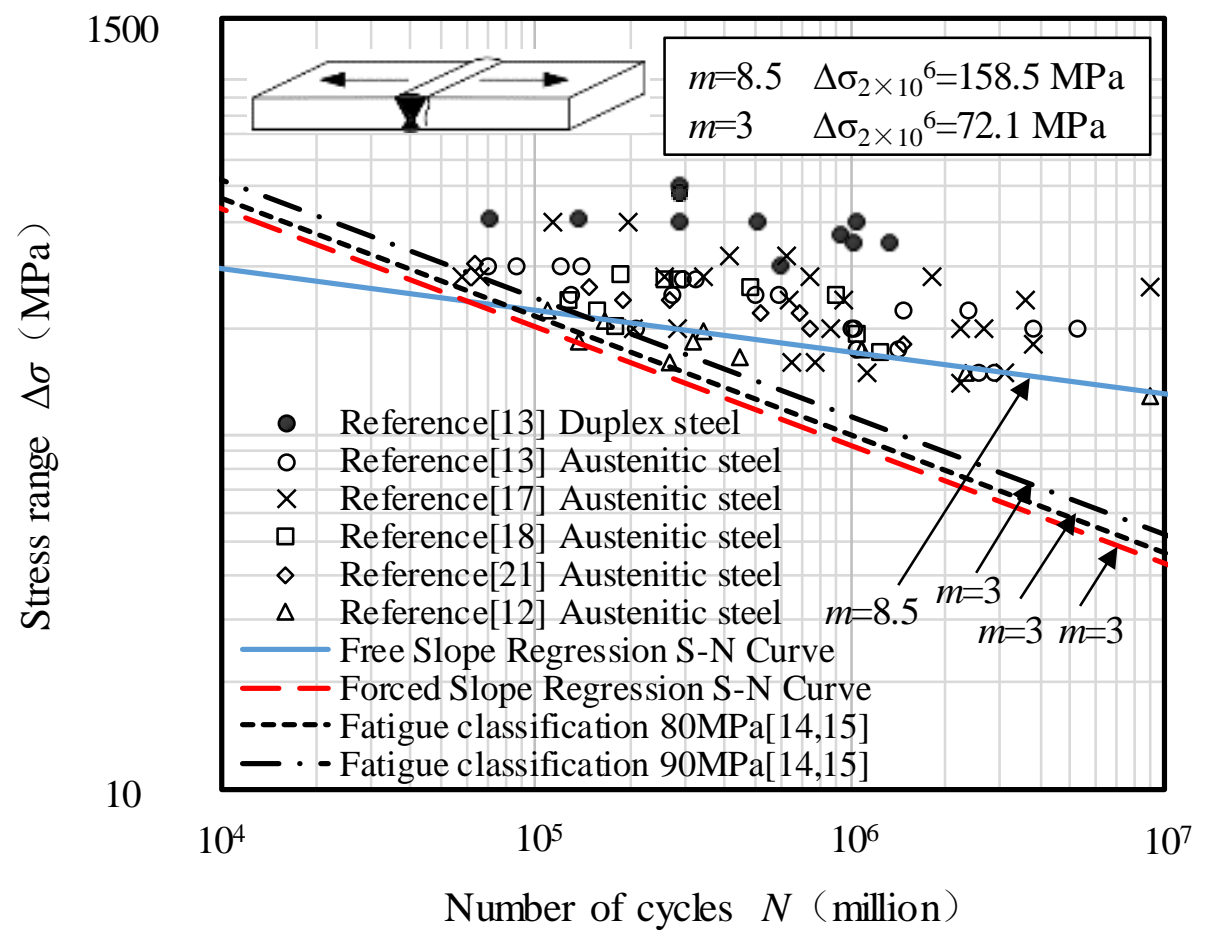

(a)

Figure 2. Cont. 


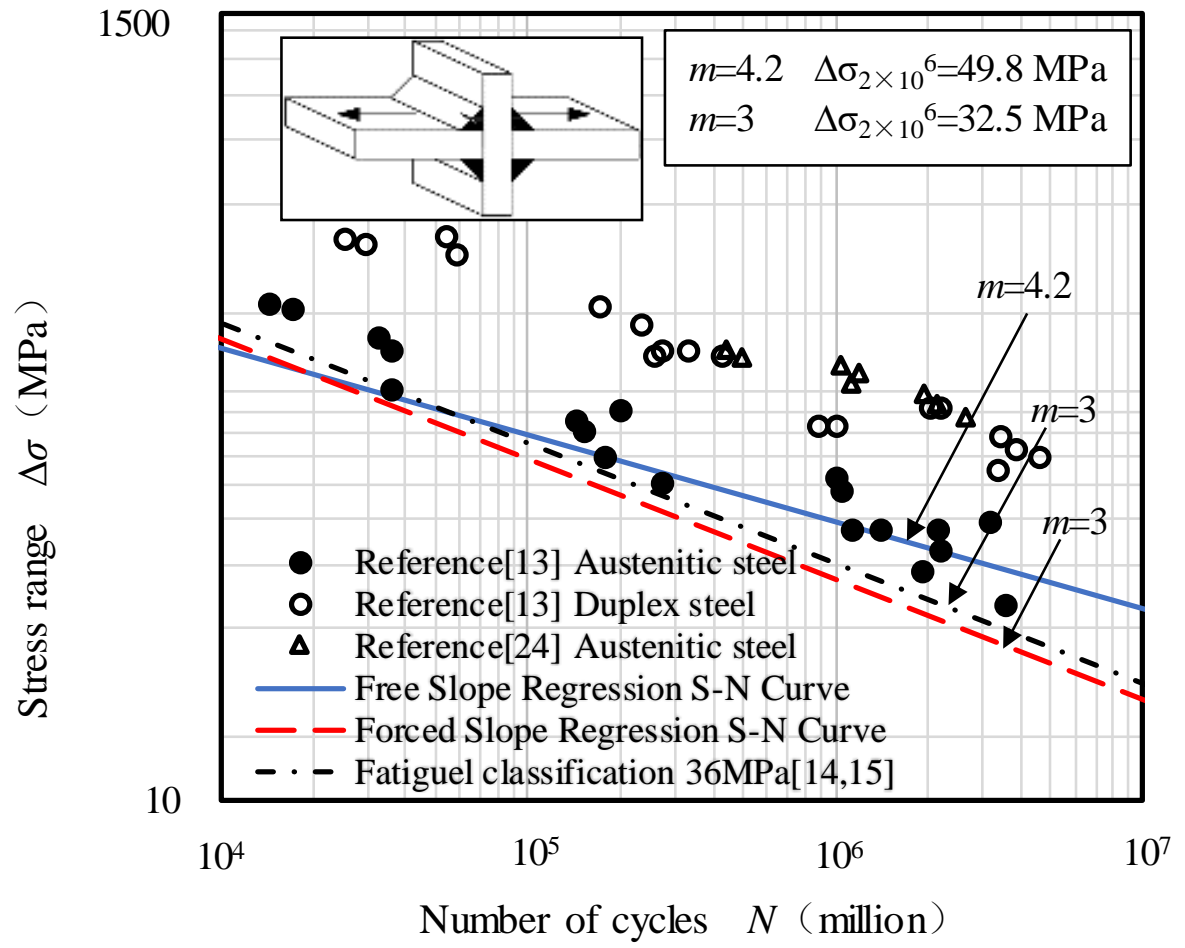

(b)

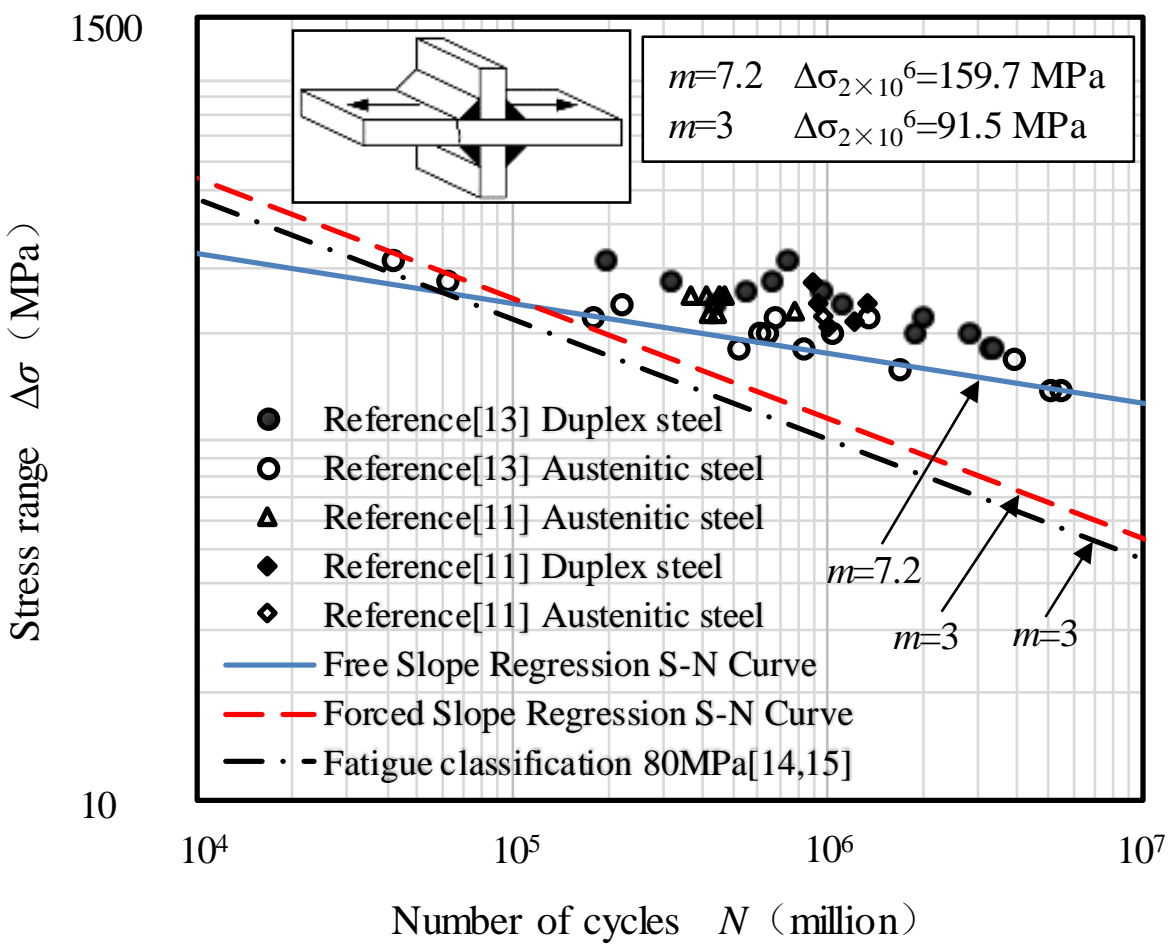

(c)

Figure 2. Cont. 


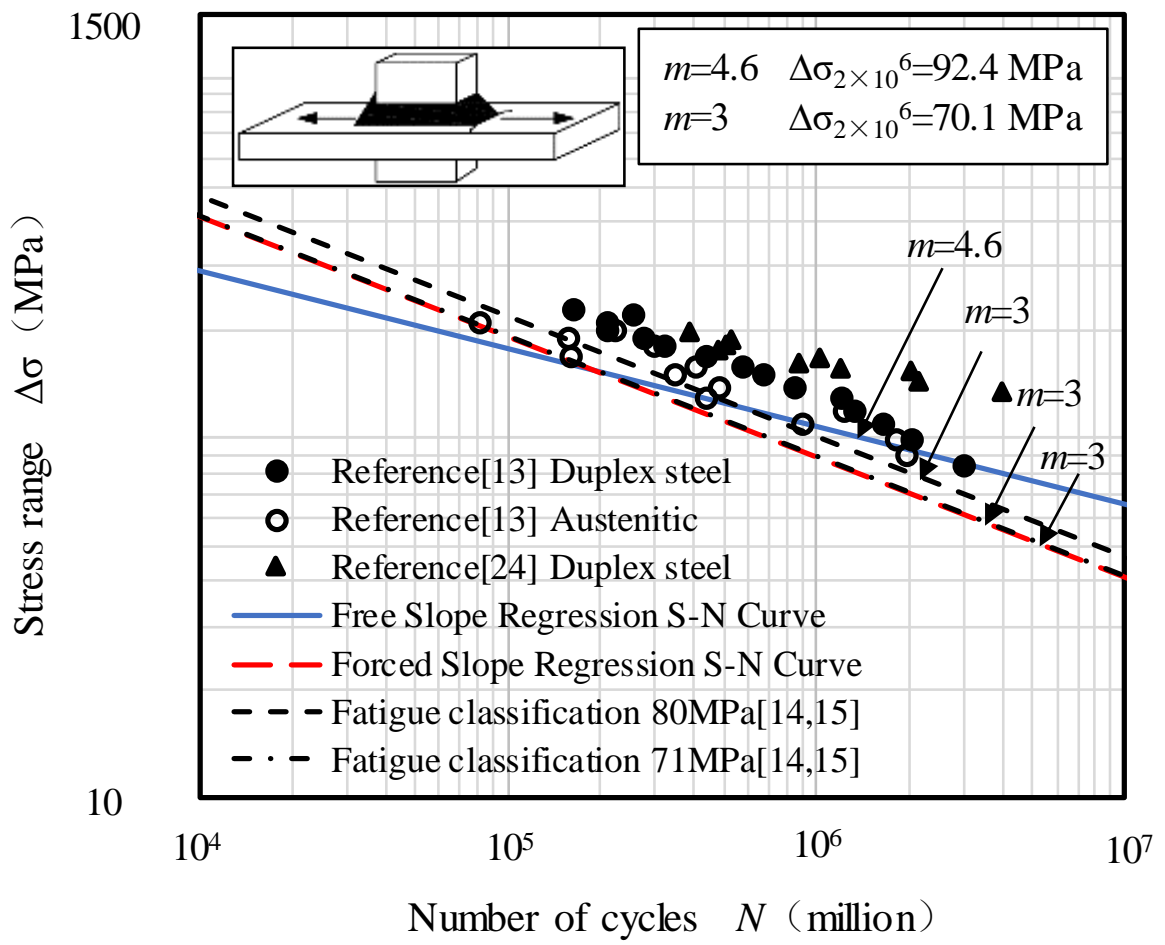

(d)

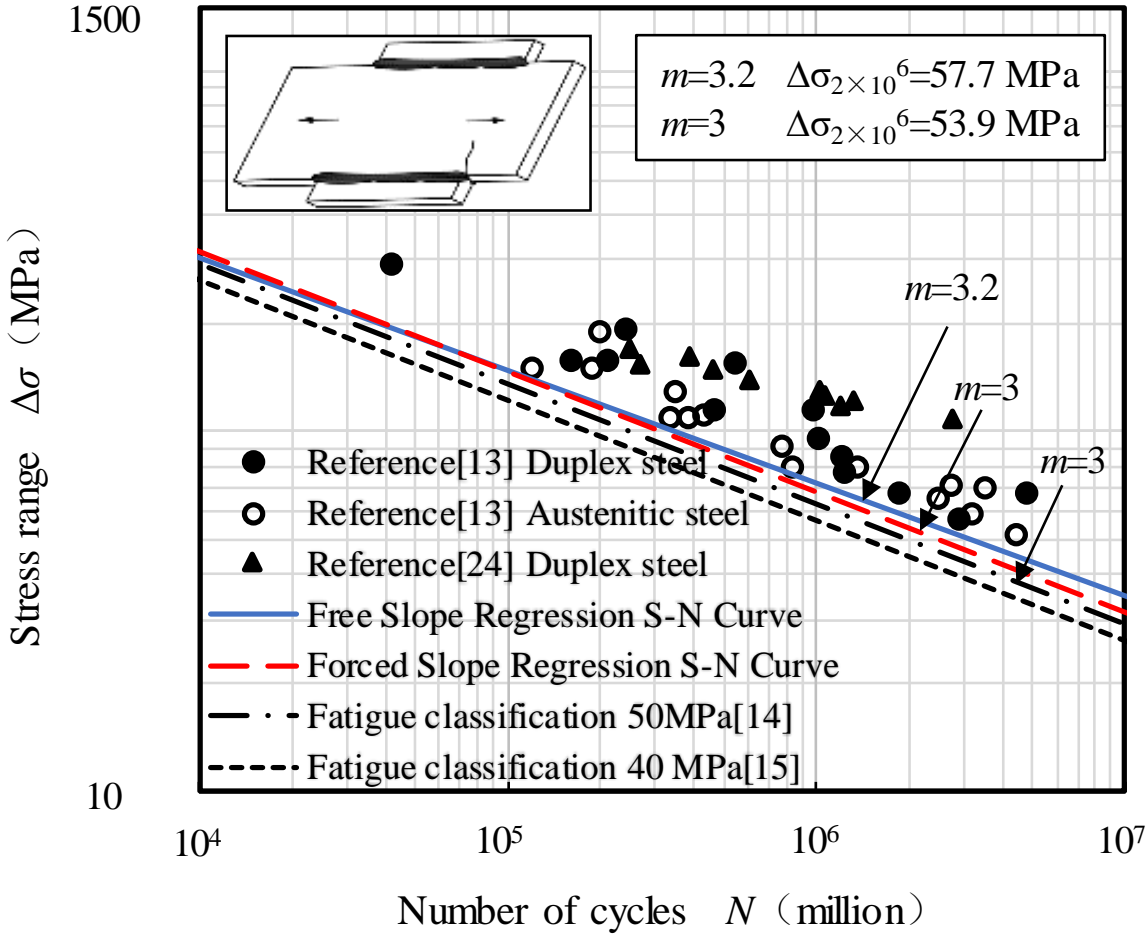

(e)

Figure 2. Cont. 


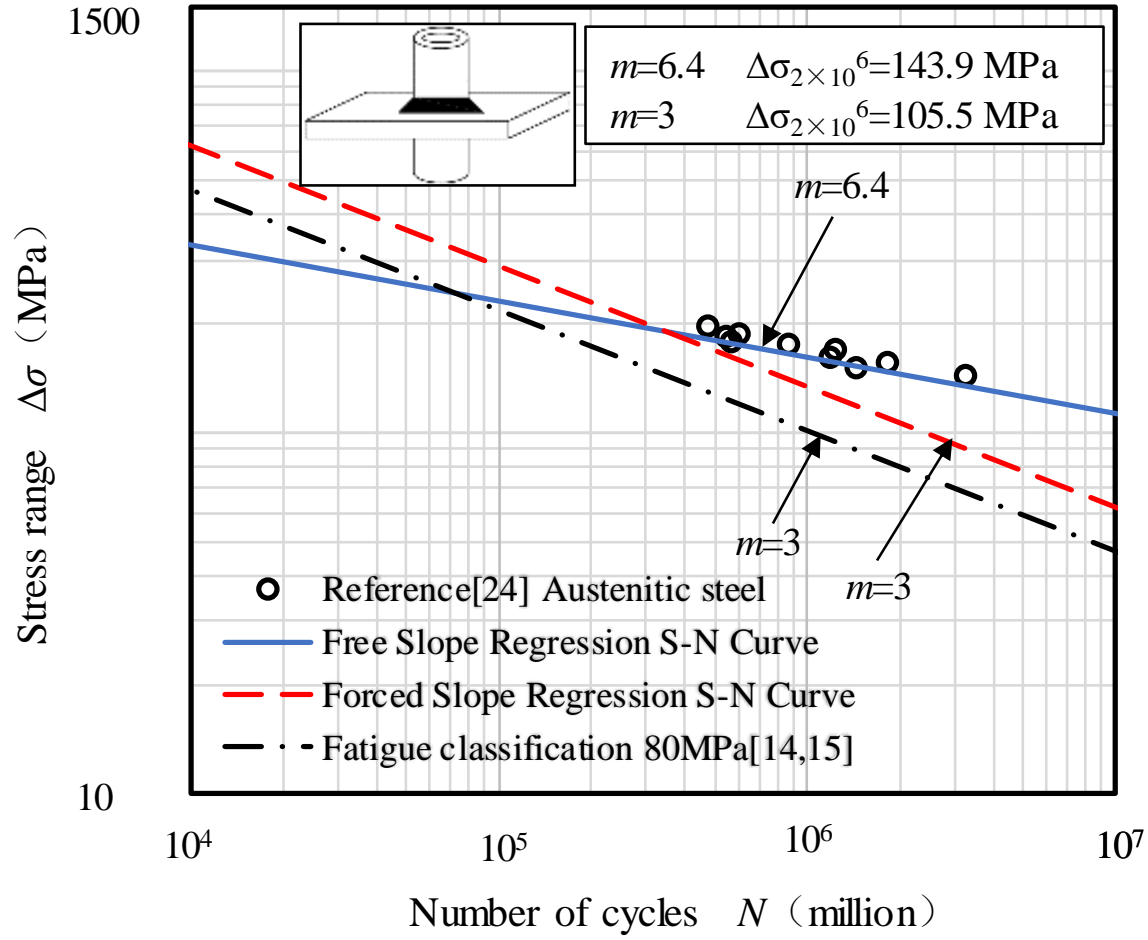

(f)

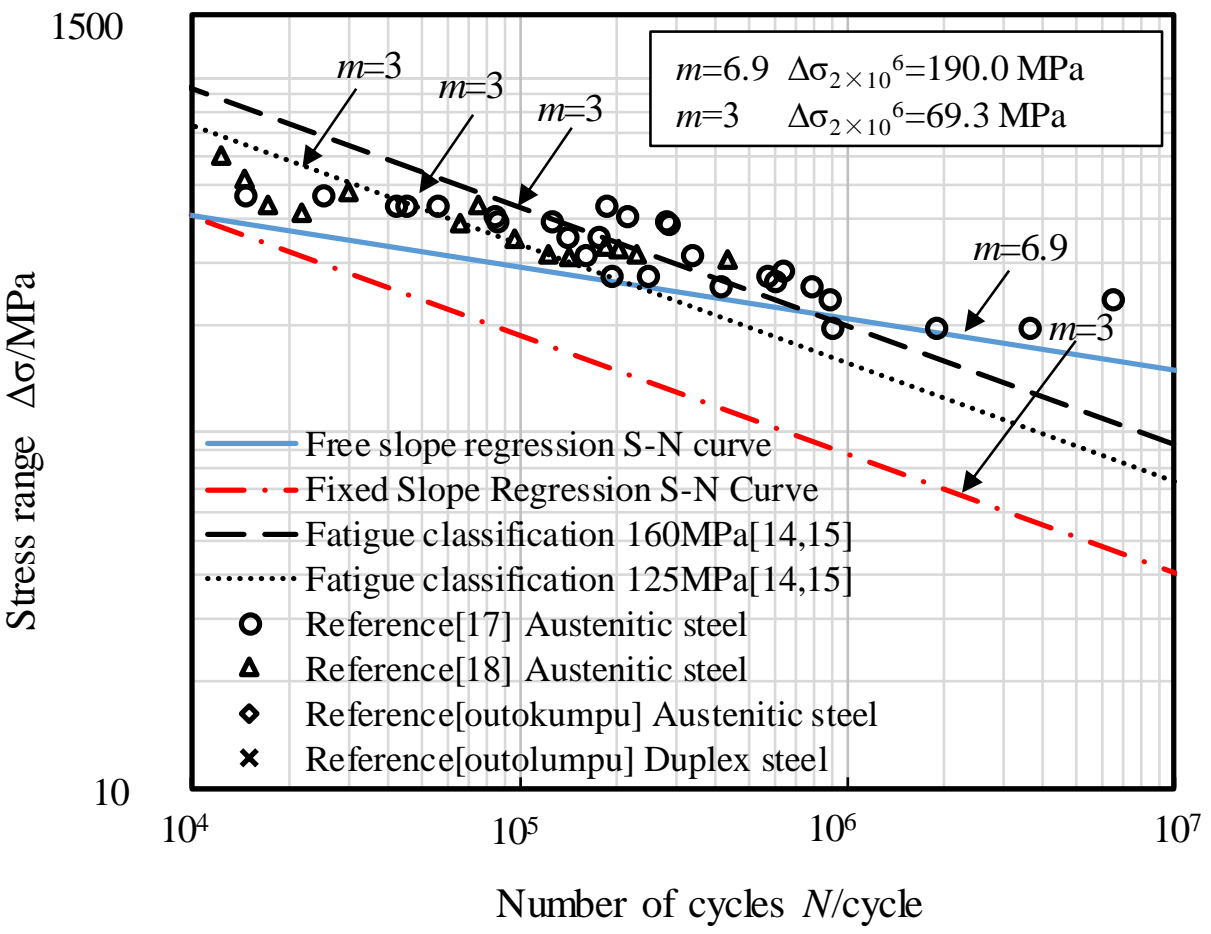

(g)

Figure 2. Characteristic $S-N$ curves of stainless-steel welds and classification curves of structural-steel welded joints: (a) butt weld; (b) cruciform joints failing in the weld throat; (c) plates with transverse fillet-welded attachments; (d) plates with longitudinal fillet-welded attachments; (e) plates with longitudinal edge gussets; (f) fillet-welded joints with longitudinal round pipes; (g) base metal. 


\subsection{Scatter Band Analysis}

There are inevitable random errors in the fatigue test, which are caused by random changes in the material properties, random errors in the specimen welding process, and random errors in the test loading devices and data testing equipment. The ratio $T_{\sigma}$ is a parameter that can quantify the correlation degree between fatigue data and the dispersion of the fitting curve. The scatter index of the $S-N$ curves is an important indicator of the quality of the assessment $[40,42]$. The scatter index $1 / T_{\sigma}$ was derived from the following equation:

$$
1 / T_{\sigma}=\frac{\Delta \sigma_{p_{S}=10 \%}}{\Delta \sigma_{p_{S}=90 \%}}
$$

As shown in Figure $3, \Delta \sigma_{P S}=10 \%$ and $\Delta \sigma_{P S}=90 \%$ are the stress ranges corresponding to two million cycles of fatigue lives of the $S-N$ curves with a probability of survival of $10 \%$ and $90 \%$, respectively, and a confidence level of $75 \%$ [40]. $\Delta \sigma_{P S=10 \%}$ and $\Delta \sigma_{P S}=90 \%$ were calculated using Equation (7).

$$
\Delta \sigma_{p_{s}}=\Delta \sigma_{p_{s}=50 \%}\left[\frac{2 \cdot 10^{6}}{10^{\log \left(2 \cdot 10^{6}\right) \pm k \cdot \sigma}}\right]^{-m} .
$$

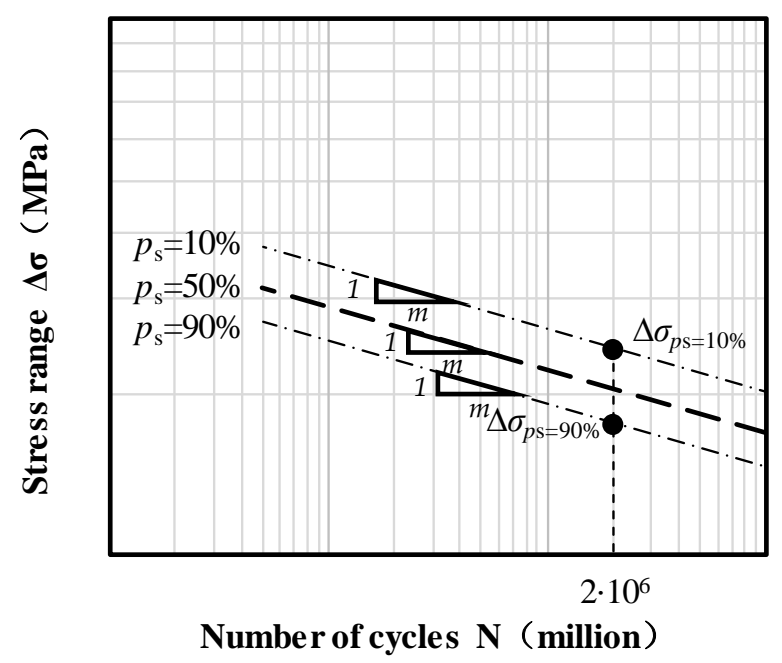

Figure 3. Scatter indexes.

Table 3 shows the scatter indexes of the fatigue test data. The scatter index of the free slope regression was smaller than that of the fixed slope regression. The average scatter index was 1.3 and the standard deviation was 0.5 with free slope regression, while the average scatter index was 1.9 and the standard deviation was 0.7 with fixed slope regression.

Table 3. Scatter indexes of the characteristic $S-N$ curve of a typical weld structure.

\begin{tabular}{ccc}
\hline Weld Structure & Free Slope Regression & Fixed Slope Regression \\
\hline Butt weld & 1.4 & 2.6 \\
Cruciform joints failing in the weld throat & 2.1 & 3.0 \\
Plates with transverse fillet-welded attachments & 1.3 & 2.0 \\
Plates with longitudinal fillet-welded attachments & 1.4 & 1.6 \\
Plates with longitudinal edge gussets & 1.5 & 1.6 \\
Fillet-welded joints with longitudinal round pipes & 1.1 & 1.4 \\
Base metal & 1.3 & 2.4 \\
Average value & 1.3 & 1.9 \\
Standard deviation & 0.5 & 0.7 \\
\hline
\end{tabular}


When Spindel and Haibach [43] analyzed a large number of fatigue test data points of welded joints of structural steel, the scatter index $1 / T_{\sigma}$ of the free slope regression $S-N$ curve was 1.5 , which is commonly used as an international standard [44,45].

The above analysis shows that, for typical welded joints of stainless steel, the scatter index obtained by free slope regression was smaller than that obtained by fixed slope regression, and was smaller than the international standard. The free slope regression $S-N$ curve can be used as the basis for fatigue design.

\subsection{Suggestions on Fatigue Strength}

Fatigue test data of duplex stainless steel and austenitic stainless steel were included in all welded joints except for the longitudinal fillet-weld structure. Regression of an $S-N$ curve with a fixed slope of 3 was used to compare the fatigue properties of austenitic stainless steel and duplex stainless steel within the matching welded joints. It was noted that the fatigue strength of duplex welded joints of stainless steel was not significantly different from that of austenitic welded joints of stainless steel.

Fatigue classification curves are given in Figure 2 for comparison with the experimental data. As can be seen from Figure 2, for the butt welds, plates with transverse fillet-welded attachments, and fillet-welded joints with longitudinal round pipes, the fatigue test data points were significantly higher than that of the fixed regression $S-N$ curve. Fatigue test data of the cruciform joints failing in the weld throat, plates with longitudinal fillet-welded attachments, and a rectangular joint plate were close to the fixed regression $S-N$ curve. The fatigue strength obtained by free slope regression was higher than the fatigue classification of structural-steel welded joints. The fatigue strength of stainless-steel welded joints is greater than that of structural-steel welded joints because of the different residual stress. Yuan [26] verified through experiments that the welding residual stress of a welded beam of stainless steel was less than that of structural steel. The linear elastic stage of stainless steel is shorter than that of structural steel, and the tangential modulus decreases rapidly. In materials with non-linear stress-strain curves, the strain required to achieve an equivalent yield stress is higher than that required to reach the unique yield point of traditional structural steel. The residual stress of stainless steel is lower than that of structural steel due to the different constitutive relationship [26]. The heat input of a stainless-steel weld is lower than that of a structural-steel weld due to the higher electrical resistance of stainless steel [26]. This is another reason for the low residual stress of the stainless-steel weld. As demonstrated in the literature [13], the butt weld, fillet-welded joints with longitudinal round pipes, and plates with transverse fillet-welded attachments had small residual stresses. According to the IIW recommendation, the fatigue strength at $2 \times 10^{6}$ cycles should be reduced by $20 \%$ to demonstrate the influence of high residual stress. Table 4 shows the reduced fatigue strength. The values are higher than the fatigue strength recommended in the EC 3 Part 1-9 and IIW recommendations. In summary, lower residual stress leads to greater fatigue strength of the stainless-steel welded joints than that of structural steel-welded joints.

Table 4. The fatigue strength of welded joints of stainless steel suggested in this paper.

\begin{tabular}{|c|c|c|c|c|c|c|c|}
\hline Weld Structure & $\begin{array}{l}\text { Butt } \\
\text { Weld }\end{array}$ & $\begin{array}{l}\text { Cruciform } \\
\text { Joints Failing } \\
\text { in the Weld } \\
\text { Throat }\end{array}$ & $\begin{array}{l}\text { Plates with } \\
\text { Transverse } \\
\text { Fillet-Welded } \\
\text { Attachments }\end{array}$ & $\begin{array}{l}\text { Plates with } \\
\text { Longitudinal } \\
\text { Fillet-Welded } \\
\text { Attachments }\end{array}$ & $\begin{array}{l}\text { Plates with } \\
\text { Longitudinal } \\
\text { Edge Gussets }\end{array}$ & $\begin{array}{l}\text { Fillet-Welded } \\
\text { Joints with } \\
\text { Longitudinal } \\
\text { Round Pipes }\end{array}$ & $\begin{array}{l}\text { Base } \\
\text { Metal }\end{array}$ \\
\hline $\begin{array}{l}\text { Fatigue strength at } \\
2 \times 10^{6} \text { cycles }(\mathrm{MPa})\end{array}$ & 155 & 45 & 155 & 90 & 55 & 140 & 190 \\
\hline
\end{tabular}

In the literature [22], the fatigue life composition of stainless-steel butt welds and plates with transverse fillet-welded attachments was analyzed using the fracture mechanics method, where it was 
found that the fatigue crack initiation life could not be neglected. Long fatigue crack initiation life will cause the $S-N$ curve slope $m$ to be much larger than $3[46,47]$. The negative inverse slopes $m$ of the $S-N$ curve were 8.5, 7.2, and 6.4 for butt welds, plates with transverse fillet-welded attachments, and fillet-welded joints with longitudinal round pipes, respectively, which were much larger than 3 . The negative inverse slopes $m$ of the $S-N$ curve were $4.2,4.6,3.2$, and 6.9 for cruciform joints failing in the weld throat, plates with longitudinal fillet-welded attachments, plates with longitudinal edge gussets, and base metal, respectively, which were close to 3 . The fatigue strengths of the butt welds, plates with transverse fillet-welded attachments, fillet-welded joints with longitudinal round pipes, and base metal were $158.5 \mathrm{MPa}, 159.7 \mathrm{MPa}, 143.9 \mathrm{MPa}$, and $190 \mathrm{MPa}$, respectively. When $S-N$ curves were regressed freely, the fatigue limit of base metal at $10^{7}$ cycles obtained from the test data was $150 \mathrm{MPa}$, and it was within the range of the fatigue limit in the reference [48]. The fatigue strengths of cruciform joints failing in the weld throat, plates with longitudinal fillet-welded attachments, and plates with longitudinal edge gussets were $49.8 \mathrm{MPa}, 92.4 \mathrm{MPa}$, and $57.7 \mathrm{MPa}$, respectively, when $S-N$ curves were regressed freely.

Based on the above analysis, the fatigue strengths of the six typical welded joints of stainless steel are suggested in Table 4.

\section{Conclusions}

The main conclusions of this study are as follows:

(1) For the same representative welded joints, the fatigue strength of welded joints of stainless steel was greater than that of the structural-steel welded joints, especially for butt welds, plates with transverse fillet-welded attachments, and fillet-welded joints with longitudinal round pipes.

(2) The scatter index $1 / T_{\sigma}$ for the free slope $S-N$ curves was 1.3 , and the scatter index $1 / T_{\sigma}$ for fixed slope $S-N$ curves, $m=3$, was 1.9. This demonstrates that the scatter band of the free slope S-N curves is much smaller than that of the fixed slope $S-N$ curves. The free slope $S-N$ curves are more suitable to represent the fatigue performance of the stainless-steel welded joints.

(3) The accuracy of analysis can be increased by adopting the slope of the $S-N$ curve according to welding details. Data analysis shows that the slope of the $S-N$ curve is between 3.2 and 8.6. With the decrease in the stress concentration, the deviation between the negative inverse slope $m$ and 3 is greater. This is why the IIW recommendation and EC 3 design $S-N$ curves were used to over-conservatively evaluate the test results.

\section{Expectation}

The experimental data collected in this paper were all from laboratory specimens, which were different from the actual sizes of the components. It is necessary to supplement these data by verifying full-scale tests under a tangible engineering environment.

Author Contributions: Y.P., J.C., and J.D. prepared the figures and drafted the manuscript. All authors critically revised and approved the final manuscript version.

Funding: This research was funded by the Project of National Natural Science Foundation of China grant number [51408307] and the Project of Nanjing Gongdajianshe Company grant number [2019RD06].

Conflicts of Interest: The authors declare no conflict of interest.

\section{References}

1. Wang, Y.; Yuan, H.; Shi, Y.; Gao, B.; Dai, G.X. Application and research status of stainless steel structure. Steel Struct. 2010, 2, 1-12. (In Chinese)

2. Baddoo, N.R.; Kosmač, A. Sustainable Duplex Stainless Steel Bridges [DB/OL]. 2012. Available online: http://www.worldstainless.org/Files/issf/non-image-files/PDF/Sustainable_Duplex_Stainless_Steel_ Bridges.pdf (accessed on 13 March 2018). 
3. Beletski, A. Applicability of Stainless Steel in Road Infrastructure Bridges by Applying Life Cycle Costing. Master's Thesis, Helsinki University of Technology, Espoo, Finland, 1 May 2007.

4. Morgenthal, G.; Sham, R.; West, B. Engineering the tower and main span construction of stonecutters bridge. J. Bridge Eng. 2010, 15, 144-152. [CrossRef]

5. Baddoo, N.; Francis, P. Development of design rules in the AISC design guide for structural stainless steel. Thin Walled Struct. 2014, 83, 200-208. [CrossRef]

6. Tsakopoulos, P.A.; Fisher, J.W. Full-scale fatigue tests of steel orthotropic decks for the Williamsburg Bridge. J. Bridge Eng. 2003, 8, 323-333. [CrossRef]

7. Ya, S.; Yamada, K.; Ishikawa, T. Fatigue evaluation of rib-todeck welded joints of orthotropic steel bridge deck. J. Bridge Eng. 2010, 16, 492-499. [CrossRef]

8. Aygul, M.; Al-Emrani, M.; Urushadze, S. Modelling and fatigue life assessment of orthotropic bridge deck details using FEM. Int. J. Fatigue 2012, 40, 129-142. [CrossRef]

9. Sim, H.B.; Uang, C.M.; Sikorsky, C. Effects of fabrication procedures on fatigue resistance of welded joints in steel orthotropic decks. J. Bridge Eng. 2009, 14, 366-373. [CrossRef]

10. Lahti, K.E.; Hänninen, H.; Niemi, E. Nominal stress range fatigue of stainless steel fillet welds-The effect of weld size. J. Constr. Steel Res. 2000, 54, 161-172. [CrossRef]

11. Burgan, B.; Baddoo, N.; Gardner, L.; Way, L.; Johansson, B.; Olssen, A.; Sélen, E.; Viherma, R.; Kouhi, J.; Talja, A.; et al. Development of the Use of Stainless Steel in Construction; European Commission: Brussels, Belgium, 1999.

12. Razmjoo, G.R. Design Guidance on Fatigue of Welded Stainless Steel Joints. In Proceedings of the International Conference on Offshore Mechanics and Arctic Engineering, Copenhagen, Denmark, 18-22 June 1995.

13. Branco, C.M.; Maddox, S.J.; Sonsino, C.M. Fatigue Design of Welded Stainless Steels; European Commission: Brussels, Belgium, 1998.

14. Hobbacher, A.F. Recommendations for Fatigue Design of Welded Joints and Components, 2nd ed.; IIW document IIW-2259-I5 ex XIII-2460-13/XV-1440-13; International Institute of Welding: Cambridge, UK, 2016.

15. Eurocode 3, Design of Steel Structures-Part 1-9: Fatigue; EN 1993-1-9; European Committee for Standardization: London, UK, 2005.

16. Metrovich, B.; Fisher, J.W.; Yen, B.T.; Kaufmann, E.J.; Cheng, X.; Ma, Z. Fatigue strength of welded AL-6XN superaustenitic stainless steel. Int. J. Fatigue 2003, 25, 1309-1315. [CrossRef]

17. NIMS. Data Sheets on Fatigue Crack Propagation Properties for Butt Welded Joints SUS304-HP(18Cr-9Ni) Hot Rolled Stainless Steel Plate. 1986. Available online: http://smds.nims.go.jp/openTest/en/content/fatiguelist. html (accessed on 3 September 2018).

18. Nakamura, Y.; Chihiro, I.; Mimura, H. Research on for Fatigue Strength of Austenitic Stainless Steel (Effects of Stress Ratio and Corrositive Environment). Kou Kouzou Rombunshuu 2009, 16, 55-64. (In Japanese)

19. Nakamura, Y.; Chihiro, I.; Hiroaki, M. Study on fatigue strength of austenitic stainless steel. J. Struct. Constr. Eng. (Trans. AIJ) 2010, 16, 55-64. (In Japanese)

20. Japanese Society of Steel Construction. Fatigue Design Recommendation for Steel Structures; Japanese Society of Steel Construction: Tokyo, Japan, 1995.

21. Singh, P.J.; Guha, B.; Achar, D.G.R. Fatigue life prediction for AISI 304L butt welded joints having different bead geometry using local stress approach. Sci. Technol. Weld. Join. 2003, 8, 303-308. [CrossRef]

22. Singh, P.J.; Achar, D.G.R.; Guha, B. Fatigue life prediction of gas tungsten arc welded AISI 304L cruciform joints different LOP sizes. Int. J. Fatigue 2003, 25, 1-7. [CrossRef]

23. BS 5400-10:1980. Steel Concrete and Composite Bridges, Code of Practice for Fatigue; British Standards Institution: London, UK, 1980.

24. Wu, B.; Yang, X.; Jia, F.; Huo, L. Experimental study on fatigue strength of welded joint of stainless steel. Mech. Strength 2004, 26, 321-325. (In Chinese)

25. Yu, W.W.; LaBoube, R.A. Cold-Formed Steel Design, 4th ed.; John Wiley \& Sons, Inc.: Hoboken, NJ, USA, 2010.

26. Yuan, H.X.; Wang, Y.Q.; Shi, Y.J.; Gardner, L. Residual stress distributions in welded stainless steel sections. Thin Walled Struct. 2014, 79, 38-51. [CrossRef]

27. Partanen, T.; Niemi, E. Hot spot stress approach to fatigue strength analysis of welded components: Fatigue test data for steel plate thicknesses up to $10 \mathrm{~mm}$. Fatigue Fract. Eng. Mater. Struct. 1996, 19, 709-722. [CrossRef] 
28. Jia, F.-Y.; Huo, L.-X.; Wu, B.; Yang, X.-Q.; Jin, X.-J. Evaluation on fatigue strength of duplex stainless steel welded joints by hot spot stress. J. Tianjin Univ. 2004, 37, 1014-1017. (In Chinese)

29. Feng, R.; Young, B. Stress Concentration Factors of Cold-formed Stainless Steel Tubular X-joints. J. Constr. Steel Res. 2013, 91, 26-41. [CrossRef]

30. Livieri, P.; Lazzarin, P. Fatigue strength of steel and aluminium welded joints based on generalised stress intensity factors and local strain energy values. Int. J. Fract. 2005, 133, 247-276. [CrossRef]

31. Meneghetti, G.; Lazzarin, P. The peak stress method for fatigue strength assessment of welded joints with weld toe or weld root failures. Weld. World 2011, 55, 22-29. [CrossRef]

32. Infante, V.; Branco, C.M.; Martins, R. a fracture mechanics analysis on the fatigue behaviour of sruciform joints of duplex stainless steel. Fatigue Fract. Eng. Mater. Struct. 2003, 26, 791-810. [CrossRef]

33. Singh, P.J.; Guha, B.; Achar, D.R.G. Fatigue tests and estimation of crack initiation and propagation lives in AISI 304L butt-welds with reinforcement intact. Eng. Fail. Anal. 2003, 10, 383-393. [CrossRef]

34. Singh, P.J.; Guha, B.; Achar, D.R.G.; Nordberg, H. Fatigue life prediction improvement of AISI 304L cruciform welded joints by cryogenic treatment. Eng. Fail. Anal. 2003, 10,1-12. [CrossRef]

35. Trudel, A.; Lévesque, M.; Brochu, M. Microstructural effects on the fatigue crack growth resistance of a stainless steel CA6NM weld. Eng. Fract. Mech. 2014, 115, 60-72. [CrossRef]

36. Maddox, S.J. Fatigue design rules for welded structures. Prog. Struct. Eng. Mater. 2015, 2, 102-109. [CrossRef]

37. Gurney, T.R.; Saunders, H. Fatigue of Welded Structures, 2nd ed.; Cambridge University Press: Cambridge, UK, 1979.

38. Maddox, S.J. Status review on fatigue performance of fillet welds. J. Offsh. Mech. Arct. Eng. 2008, 130, 1469-1476. [CrossRef]

39. ISO 12107-2003. Metallic Materials_Fatigue Testing_Statistical Planning and Analysis of Data; ISO: Geneva, Switzerland, 2003.

40. Schneider, C.R.A.; Maddox, S.J. Best Practice Guide on Statistical Analysis of Fatigue Data; Comission: XIII-WG1-114-03; Internatinal Institute of Welding: Cambridge, UK, 2003.

41. Baptista, C.; Reis, A.; Nussbaumer, A. Probabilistic S-N curves for constant and variable amplitude. Int. J. Fatigue 2017, 101, 312-327. [CrossRef]

42. Zhang, Y. Research on Mechanical Properties and Design Method of Stainless Steel Weld Joints. Ph.D. Thesis, Beijing University of Technology, Beijing, China, 20 June 2016. (In Chinese)

43. Spindel, J.E.; Haibach, E. The method of maximum likelihood applied to the statistical analysis of fatigue data including run-outs. Int. J. Fatigue 1979, 1, 81-88. [CrossRef]

44. Knight, J.W. Some Basic Fatigue Data for Various Types of Fillet Welded Joints in Structured Steel; Welding Institute Members Report 9/1976/E; The Welding Institute: Cambridge, UK, 1976.

45. Maddox, S.J. Assessing the significance of flaws in welds subjects to fatigue. Weld. J. Weld. Res. Suppl. 1974, 53, 401-409.

46. Atzori, B.; Lazzarin, P.; Meneghetti, G.; Ricotta, M. Fatigue design of complex welded structures. Int. J. Fatigue 2009, 31, 59-69. [CrossRef]

47. Peng, Y. Fatigue Behavior of Butt Welded Joints between Cast Steel and Rolled Steel Based on Experimental Study and Fracture Mechanics Analysis. Ph.D. Thesis, Tongji University, Shanghai, China, 20 December 2012. (In Chinese)

48. De Finis, R.; Palumbo, D.; Ancona, F.; Galietti, U. Fatigue limit evaluation of various martensitic stainless steels with new robust thermographic data analysis. Int. J. Fatigue 2015, 74, 88-96. [CrossRef]

(C) 2019 by the authors. Licensee MDPI, Basel, Switzerland. This article is an open access article distributed under the terms and conditions of the Creative Commons Attribution (CC BY) license (http://creativecommons.org/licenses/by/4.0/). 